\title{
The impact of community-based health insurance on health-related quality of life and associated factors in Ethiopia: a comparative cross-sectional study
}

\author{
Teklemichael Gebru* and Kifle Lentiro
}

\begin{abstract}
Background: Quality of life can be used to measure the effect of intervention on health related conditions. Health insurance contributes positive effect on availability of medical supplies and empowerment of women and children on financial healthcare. Therefore, the study was aimed to measure the impact of Community-Based Health Insurance on HRQoL and associated socio-demographic factors.

Methods: A comparative community based cross-sectional study was employed. Data was collected by trained enumerators using World Health Organization QoL-BREF tool from a sample of 1964 (982 CBHI insured and 982 un-insured) household heads selected by probability proportional to size. A descriptive summery, simple and multiple linear regression analysis was applied to describe the functional predictors of HRQoL. The study was ethically approved by IRB of Wolkite University.
\end{abstract}

Results: The HRQOL score among CBHI insured family heads was 63.02 and 58.92 for un-insured family heads. The overall variation in HRQoL was explained due to; separated marital condition which reduced the HRQoL by $4.30 \%$ than those living together $\left[{ }^{\beta}=-0.044,95 \% \mathrm{Cl}(-5.67,-0.10)\right]$, daily laborer decreased HRQoL by $7.50 \%{ }^{\beta}=-0.078$, $95 \% \mathrm{Cl}(-12.91,-4.10)]$, but employment increased by $5.65 \%$ than farmers $\left[{ }^{\beta}=0.055,95 \% \mathrm{Cl}(2.58,17.59)\right]$. QoL increased by 6.4 and $6.93 \%$ among primary and secondary level educated household heads than those household heads who could not read and write $\left[{ }^{\beta}=0.062,95 \% \mathrm{Cl}(0.75,4.31)\right]$ and $\left[^{\beta}=0.067,95 \% \mathrm{Cl}(1.84,7.99)\right]$, respectively. As family size increased by one households' head, HRQoL decreased by $18.21 \%\left[^{\beta}=-0.201,95 \% \mathrm{Cl}(-2.55,-1.63)\right]$, as wealth index increased by one unit, HRQoL decreased by $32.90 \%\left[{ }^{\beta}=-0.306,95 \% \mathrm{Cl}(-5.15,-3.86)\right]$ and QoL among CBHI insured household heads increased by $12.41 \%$ than those un-insured family heads $\left[{ }^{\beta}=0.117,95 \% \mathrm{Cl}\right.$ $(2.98,6.16)]$.

Conclusions: The study revealed that significant difference in quality of life was found among the two groups; health insurance had positive effect on quality of life. Triggered, the government shall expand the scheme into other similar areas' and further efforts should be made on the scheme service satisfaction to ensure its continuity.

Keywords: Household head, Health insurance, Quality of life

\footnotetext{
* Correspondence: teklemichaelgebru@gmail.com; tekle.gebru@wku.edu.et Department of Public Health, College of Medicine and Health Science, Wolkite University, Addis Ababa, Ethiopia

(c) The Author(s). 2018 Open Access This article is distributed under the terms of the Creative Commons Attribution 4.0 International License (http://creativecommons.org/licenses/by/4.0/) which permits unrestricted use, distribution, and reproduction in any medium, provided you give appropriate credit to the original author(s) and the source, provide a link to the Creative Commons license, and indicate if changes were made. The Creative Commons Public Domain Dedication waiver (http://creativecommons.org/publicdomain/zero/1.0/) applies to the data made available in this article, unless otherwise stated.
} 


\section{Background}

In terms health related indicators; Ethiopia ranks low even as compared to other low income countries [1]. The country bears high burden of preventable communicable diseases. According to the country ministry of health $(\mathrm{MoH}) 2015$ report, the top leading causes of mortality were malaria, pneumonia and respiratory tract diseases $[2,3]$. In spite to this high burden, utilization of modern health care services is limited [3]. One of the reasons for low utilization of healthcare services is the direct user-fee charges [4].

In Ethiopia, 38.5\% of the total health expenditure was covered through out-of-pocket charges, which is higher than that of other African countries, which was $30.6 \%$ in 2008 [3, 5]. Nevertheless, Ethiopia's per capita public spending for health (14 US\$ in 2008) remains far below even that of other African and low income countries (83 US\$ and 32 US\$, respectively in 2008) [5].

Health care expenses are devastating and have long term effect on economic situations to majority of household heads in Ethiopia. Consequently, it was suggested that alternative mechanisms such as health taxes should be established to cover health care expenses [6]. Moving away from out of pocket charges for healthcare at the time of use is an important step towards in averting the financial hardship related with paying for health service [7]. But, in 2008 the government planned to cover the prepaid only $1.5 \%$ of the total private expenditure on health in Ethiopia [5].

To increase the prepaid plan coverage and access to modern health care services, the Ethiopian government has introduced Community Based Health Insurance (CBHI). The scheme was piloted since 2011 in 13 districts with the objective to draw a lesson for scale-up at countrywide level. Currently the scheme covers 202 districts, including 52 from South Nation Nationality People's Region (SNNPR). Increased and improved cash flow has had a positive effect on the availability of medications and other supplies, which turn to improve the quality of health services. However, there is no quantified evidence whether the $\mathrm{CBHI}$ may contribute to Health-Related Quality of Life (HRQoL) or yet not. Therefore, the purpose of this study was to assess the impact of CBHI on health-related quality of life. It was believed that this study will helps to provide evidence based decisions by policy makers to benefit the community of the country and beyond.

\section{Methods}

\section{Study area and period}

The study was conducted in SNNPR which is one of the largest regions in Ethiopia, covers for more than $10 \%$ of the country's land area with an estimated $112,343.19 \mathrm{~km}^{2}$. Based on 2016 point estimate, the region has a population of 15,927,649, including 7,916,042 men and 8,011,607 women. The region was administratively divided into 13 zones, 133 Woredas (administrative levels higher than kebeles) and 3512 Kebeles (the smallest administrative level in the country). Healthcare service of the region was renders through 45 Hospitals, 248 Health Centers and 3729 Health Posts. The study was conducted in Dale Woreda (Yirgalem) as a best pilot CBHI implementer since 2011 and non-CBHI covered Gorche Woreda which has similar socio-demographic character with the piloted Woreda (Yirgalem) [8]. The study was employed in February, 2017.

\section{Study design and population}

A community based comparative cross-sectional study was employed. Source populations of the study were all household heads whereas households heads found in randomly sampled household heads' were study population. Household heads reside at least for six months in the study area were included in the study however household heads' who were included in to the scheme within six months of the study were excluded to minimize immature effect of the scheme.

\section{Sample size determination and procedure}

Sample size was calculated using STATCALC program of EPI INFO version 7 statistical packages for windows by assuming; mean score $2.4( \pm 0.8)$ difference of HRQoL (as outcome variable), 95\% confidence interval $\left(\mathrm{Z} \alpha_{/ 2}\right), 80 \%$ power, insured and un-insured household head ratio of $1: 1$, and $10 \%$ expected non-response rate [8]. Accordingly, the required sample size was 1967 household heads. The best CBHI pilot implementation performer of the country Dale Woreda was selected as CBHI covered Woreda and Gorche Woreda as non-CBHI covered Woreda which has similar socio demographic character was selected, in these two Woredas there were 36 and 22 Kebeles, and 48,971 and 23,705 households, respectively. Sampling frame was prepared with cumulative frequency for each district [8]. Then independently for each district probability proportional to size sampling method was used to select the sampling unit household. Accordingly, we plan to collect data and distributed a questionnaire of 1967 that consists socio-demographic and HRQoL related issues.

\section{Data collection and quality assurance}

An adapted World Health Organization Quality of Life Biomedical Research and Educational Facility (WHOQoL-BREF) data collection tool was used in this study. First, the tool was adopted in English then translated into Amharic and finally back translated in to English by another expert to keep its consistency. The tool consists two items on overall general health and 24 items divided 
into four domains; 7 items physical health, 6 items psychological health, 3 items social relationships and 8 items environmental health rated on five-point likert scale [9]. Twenty health extension worker data collectors and four BSc holder public health supervisors were involved in the data collection process. The overall data collection process was coordinated by researchers. Moreover, the questioner was pre-tested on $5 \%$ of the actual sample size in the area with population having similar socio-demographic status with study population.

Training was given to data collectors prior to the start of data collection process for three-day. Lecture, mock interview and field practice were included in the training process. Even through, supervisors were trained together with the data collectors; orientation was given separately on how to supervise the data collectors. Moreover, daily based check-up on $10 \%$ of the filled questionnaire each day were made and incomplete questionnaire was referred back for completion and data was validated for similarity through double data entry by Epi Data 3.1 statistical software for windows.

\section{Data processing and analysis}

The collected data was checked for completeness, edited, coded, entered to Epi-data 3.1 software and cleaned. Then for analysis it was export to Statistical Package for Social Science (SPSS) version 20.0 for windows. Descriptive summary was calculated for socio-demographic characteristics such as mean and proportions. Based on the WHOQoL-BREF guideline after inversely coding negatively coded items raw domain score was computed and transformed the total HRQoL score. Moreover, Levene's test was used to assess homogeneity of the two populations (insured and un-insured) and principal component analysis was employed for wealth index. Cronbach's alpha coefficient with 0.70 and above was accepted.

Simple linear regression was applied to see the association between factors and HRQoL as a first phase screening. To avoid unstable estimate variables with $p$-value $=<0.25$ were candidate for the final regression model [10]. Then, multiple leaner regression was applied in order to control the effect of confounding factors and to describe the functional association between the socio-demographic factors and the total score HRQoL. Beta was determined to estimate the strength of association with $95 \%$ confidence interval (CI). For all statistical significance tests, the cut- off value set is $p<0.05$.

\section{Results}

\section{Socio-demographic characteristics}

We planned to participate 1967 household heads, however, 1955 were included in the study; this makes $99.44 \%$ response rate. Among the study participants 1318
(67.4\%) were husband (male) respondents. The mean age of study participants were 40 with standard deviation of 11 years. Of the respondents $1234(72.1 \%)$ were farmers by their jobs. More than half of the study participant 1121 (57.3\%) could not read \& write. On the other hand, among the interviewed household heads, $1031(52.7 \%)$ have greater than five family size. Moreover, by their socio-demographic characteristics, the two populations were statistically homogenous only by educational status and marital condition whereas they were statistically different by age, gender, family size and wealth index (Table 1).

\section{Health related quality of life score}

Among the two group of the population, the highest mean and percentage satisfaction of HRQoL for insured family were revealed psychological domain (mean $=31.12$ $( \pm 5.65)$; percentage $=86.13)$ and un-insured were physical health domain $($ mean $=28.63( \pm 6.76)$; percentage $=66.54)$ and the lowest satisfaction of HRQoL for both group of the population were social relationship domain $($ mean $=8.86( \pm 2.94)$; percentage $=48.79)$ and $($ mean $=$ $8.67( \pm 3.62)$; percentage $=60.75)$, respectively. From the Levene's test for homogeneity, the two populations were statistically different by physical health and Psychological domains $\left(\mathrm{F}_{(1,1953)}=128.95 .77, p=<0.00\right)$ and $\left(\mathrm{F}_{(1,1953)}=\right.$ 309.61, $p=<0.00)$, respectively. The transformed total HRQoL score among CBHI insured family heads was 63.02 and 58.92 for un-insured family and the two populations were statistically different $\left(\mathrm{F}_{(1,1953)}=21.77\right.$, $p=<0.00$ ) (Table 2).

\section{Factors associated with health related quality of life}

The overall variation in HRQoL was contributed due to; separated marital condition was reduced the HRQoL by $4.30 \%$ than those living together $\left[^{\beta}=-\right.$ $0.044,95 \%$ CI $(-5.67,-0.10)]$, daily laborer household heads decreased HRQoL by $7.50 \%{ }^{\beta}=-0.078$, 95\% CI $(-12.91,-4.10)]$, but employment increased by $5.65 \%$ than those who were farmers $\left[^{\beta}=0.055\right.$, $95 \%$ CI $(2.58,17.59)]$. HRQoL among primary and secondary educated household heads increased by 6.4 and $6.93 \%$ than those household heads who could not read and write ${ }^{\beta}=0.062,95 \%$ CI $\left.(0.75,4.31)\right]$ and $\left[{ }^{\beta}=0.067,95 \%\right.$ CI $\left.(1.84,7.99)\right]$, respectively. As family size increased by one households' head, HRQoL decreased by $18.21 \%\left[{ }^{\beta}=-0.201,95 \%\right.$ CI: $(-2.55$, 1.63)]. Moreover, as wealth index increased by one unit, HRQoL decreased by $32.90 \%\left[{ }^{\beta}=-0.306,95 \%\right.$ CI $(-5.15,-3.86)]$ and HRQoL among CBHI insured household heads were increased by $12.41 \%$ than those un-insured family heads ${ }^{\beta}=0.117,95 \%$ CI $\left.(2.98,6.16)\right]$ (Table 3). 
Table 1 Socio-demographic characteristics of study participants in SNNPR, $n=1955$, February, 2017

\begin{tabular}{|c|c|c|c|c|c|c|}
\hline \multirow[t]{3}{*}{ Variable } & \multicolumn{4}{|c|}{ Household condition on CBHI } & \multirow{2}{*}{\multicolumn{2}{|c|}{ Homogeneity test }} \\
\hline & \multicolumn{2}{|l|}{ Insured } & \multicolumn{2}{|c|}{ Un-insured } & & \\
\hline & Count (n) & Percent (\%) & Count (n) & Percent (\%) & Chi-Square & $P$-value \\
\hline Respondent type & & & & & 17.74 & $<0.00$ \\
\hline Husband & 613 & 62.9 & 705 & 71.9 & & \\
\hline Wife & 361 & 37.1 & 276 & 28.1 & & \\
\hline Age in year (mean, SD) & $41( \pm 10)$ & & $40( \pm 11)$ & & 531.34 & $<0.00$ \\
\hline Current job & & & & & 40.59 & $<0.00$ \\
\hline House wife & 355 & 36.4 & 264 & 26.9 & & \\
\hline Farmer & 556 & 57.1 & 678 & 69.1 & & \\
\hline Laborer & 35 & 3.6 & 30 & 3.1 & & \\
\hline Employed & 28 & 2.9 & 9 & 0.9 & & \\
\hline Marital condition & & & & & 0.32 & 0.57 \\
\hline Live together & 872 & 89.5 & 863 & 88.0 & & \\
\hline Separate/divorce/widow & 102 & 10.4 & 118 & 12.0 & & \\
\hline Educational level & & & & & 6.34 & 0.09 \\
\hline Could not read \& write & 564 & 57.9 & 557 & 56.8 & & \\
\hline Primary & 332 & 34.1 & 344 & 35.1 & & \\
\hline Secondary and above & 78 & 8.0 & 74 & 8.1 & & \\
\hline Family size & & & & & 99.95 & $<0.00$ \\
\hline Less than or equal to 5 & 350 & 35.9 & 574 & 58.5 & & \\
\hline Greater than 5 & 624 & 64.1 & 407 & 41.5 & & \\
\hline Wealth index (quintile) & & & & & 48.57 & $<0.00$ \\
\hline Poorest & 149 & 15.30 & 129 & 13.1 & & \\
\hline Poor & 244 & 25.1 & 204 & 20.8 & & \\
\hline Medium & 244 & 26.1 & 176 & 17.9 & & \\
\hline Rich & 166 & 17.0 & 270 & 27.5 & & \\
\hline Richest & 161 & 16.5 & 202 & 20.6 & & \\
\hline
\end{tabular}

\section{Discussion}

In this study it was revealed that community based health insurance impacted the health-related quality of life among insured and un-insured family heads. Quality of life among insured household heads were higher compared with un-insured household heads; more specifically insured family heads had higher quality of life on the domain psychological and environmental health than un-insured family heads whereas low on physical health and almost equal on social relationship domain.

Quality of life scores in our study participants living separately by their marital condition were low compared with living together. This finding was consistent with

Table 2 Quality of life score among insured and un-insured household head study participants in SNNPR, $n=1955$, February, 2017

\begin{tabular}{|c|c|c|c|c|c|c|}
\hline \multirow[t]{3}{*}{ Variables } & \multicolumn{4}{|c|}{ Household condition on $\mathrm{CBH}$} & \multicolumn{2}{|c|}{ Test of Homogeneity } \\
\hline & \multicolumn{2}{|l|}{ Insured } & \multicolumn{2}{|l|}{ Un-insured } & \multirow[b]{2}{*}{$\mathrm{F}$} & \multirow[b]{2}{*}{$P$-value } \\
\hline & Mean ( \pm SD) & Transformed score & Mean ( \pm SD) & Transformed score & & \\
\hline Physical health & $22.17( \pm 6.72)$ & 54.17 & $28.63( \pm 6.76$ & 66.54 & 128.95 & $<0.00$ \\
\hline Psychological & $31.12( \pm 5.65)$ & 86.13 & $24.01( \pm 11.28)$ & 47.24 & 309.61 & $<0.00$ \\
\hline Social relationship & $8.86( \pm 2.94)$ & 48.79 & $8.67( \pm 3.62)$ & 60.75 & 1.56 & 0.21 \\
\hline Environment & $29.15( \pm 6.39)$ & 62.97 & $25.57( \pm 8.54)$ & 61.14 & 2.94 & 0.09 \\
\hline Quality of life & & 63.02 & & 58.92 & 21.77 & $<0.00$ \\
\hline
\end{tabular}


Table 3 Predictors to quality of life among household head study participants in SNNPR, $n=1955$, February, 2017

\begin{tabular}{|c|c|c|c|}
\hline \multirow[t]{2}{*}{ Variable } & \multicolumn{3}{|l|}{$\begin{array}{l}\text { Quality of life } \\
\text { Beta with } 95 \% \mathrm{Cl}\end{array}$} \\
\hline & Unstandardized & Standardized & $P$-value \\
\hline Age in year & $-0.041(-0.16,0.01)$ & $-0.038(-0.15,0.01)$ & 0.069 \\
\hline \multicolumn{4}{|l|}{ Marital condition } \\
\hline Live together & - & - & - \\
\hline Separate/divorce/widow & $-0121(-10.96,-5.12)$ & $-0.044(-5.67,-0.10)$ & 0.043 \\
\hline \multicolumn{4}{|l|}{ Educational level } \\
\hline Could not read \& write & - & - & - \\
\hline Primary & $0.130(3.53,7.14)$ & $0.062(0.75,4.31)$ & 0.005 \\
\hline Secondary and above & $0.110(4.78,11.21)$ & $0.067(1.84,7.99)$ & 0.002 \\
\hline \multicolumn{4}{|l|}{ Current job } \\
\hline Farmer & - & - & - \\
\hline Daily laborer & $-0.076(-13,06,-3.42)$ & $-0.078(-12.91,-4.10)$ & $<0.001$ \\
\hline Employer & $0.023(-4.71,15.14)$ & $0.055(2.58,17.59)$ & $<0.001$ \\
\hline Family size & $-0.332(-0.79,0.13)$ & $-0.201(-2.55,-1.63)$ & $<0.001$ \\
\hline Wealth Index & $-0.382(-8.26,-6.66)$ & $-0.399(-8.67,-6.90)$ & $<0.001$ \\
\hline \multicolumn{4}{|l|}{$\mathrm{CBH}$ condition } \\
\hline Un-insured & - & - & - \\
\hline Insured & $0.105(2.38,5.82)$ & $0.117(2.98,6.16)$ & $<0.001$ \\
\hline
\end{tabular}

reports conducted elsewhere [11]. The score represents the effect of living alone lead to deterioration of life which could be explained due to burden on taking family responsibility alone than joint care [12]. On the other hand, quality of life was markedly increased as an educational level increased. This result was consistent with the study finding conducted in nine European countries [13-15].

In addition, Study participants who engaged on daily labor during the study period negatively affected the quality of life. In contrary employed participants were positively associated for better quality of life as compared to farmers by their occupational status. This finding was similar with research report from Chinese and others [16, 17]. This effect may be explained due to job security and level of satisfaction on their job. Furthermore, the study revealed that the effect of family size and wealth index increment worth's family head's quality of life and it could be explained due to increased family responsibility.

\section{Limitation of the study}

The major limitation of this study was related to causal relationship as it was not allowed to established cause and effect relationship. Except for gross socio-demographic character such as age, marital condition, educational status and job, this study did not allow to link with other potential factors that may affect quality of life. Despite these limitations, our study provided a comprehensive opportunity to overview the effect of health insurance on health related quality of life.

\section{Conclusions}

From this work, we revealed that the two populations were different in their quality of life. Moreover, being member of community based health insurance had positive effect on health related quality of life. Triggered this, the government shall expand the community based health insurance into additional districts of Ethiopia and further actions should be established on the scheme satisfaction to ensure its continuity.

\section{Abbreviations}

CBHI: Community Based Health Insurance; HRQoL: Health Related Quality of Life; IRB: Institutional Review Board; QOL: Quality of Life; SNNPR: South Nation Nationality People's Region; SPSS: Statistical Package for Social Science; US\$: United State Dollar; WHOQoL-BREF: World Health Organization Quality of Life Biomedical Research and Educational Facility

\section{Acknowledgments}

First and foremost, we would like to express our deepest gratitude to data collectors, supervisors and the study participants for their cooperation. We extend our appreciation to Sidama zone health department for its cooperation. Finally, we would like to acknowledge Wolkite University for the financial support.

\section{Funding}

This study was financially supported only for data collection by Wolkite University, Ethiopia.

\section{Availability of data and materials}

The datasets used and analysed during the study available from the corresponding author on reasonable request. 


\section{Authors' contributions}

TG framed the study and analyzed the data and $\mathrm{KL}$ contributed to the design and data collection of the study. The manuscript was prepared by both authors and approved its final version submitted for publication.

\section{Ethics approval and consent to participate}

The study was ethically approved by the institutional review board of Wolkite University. Official letter was obtained from Wolkite university health Science College. Letter of co-operation was obtained from Sidama Zone health department after informed about the purpose and importance of the study. From the prepared information sheet; study participants were introduced about the study, their right, autonomy and their participation willingness and then written consent was obtained prior to each interview. Names and other personal information which can violate the confidentiality of the respondents was not taken or recorded. Any information was kept confidential and only used for the research purpose and not exposed to third party for any other reason. During interview privacy of respondents was kept, and free to withdrawal from the interviewed at any time.

\section{Competing interests}

The authors declare that they have no competing interests.

\section{Publisher's Note}

Springer Nature remains neutral with regard to jurisdictional claims in published maps and institutional affiliations.

Received: 29 August 2017 Accepted: 23 May 2018

Published online: 31 May 2018

\section{References}

1. Agency CS. (CSA) [Ethiopia] and ICF. Ethiopia demographic and health survey. Key Indicators Report. 2016;2016:19-59.

2. Mebratie D. Enrolment in Ethiopia's community based health insurance scheme; Erasmus International Institute of Social Studies. In: The Hague; 2013.

3. Ministry of Finance and Economic Development. Macroeconomic Developments in Ethiopia, Annual Report. Addis Ababa; 2016.

4. EThiopian $\mathrm{FMoH}$. A directive to provide legal backing for piloting and promotion of CBHI. Addis Ababa; 2011.

5. United Nations Development Programme (UNDP). Human Development Report 2011. In: Sustainability and equity: a better future for all. New York; 2011.

6. EThiopian FMoH. Health and health related indicators of 2011. Addis Ababa; 2011

7. EThiopian FMOH. Health Care Financing Team, Policy, Planning and Finance General Directorat, USAID Health Sector Financing Reform Project: Ethiopia's Fourth National Health Accounts. Addis Abeba. 2010.

8. Bureau of finance and economic development. Development data collection dissemination core process, annual statistics. In: SNNPR Hawassa; 2016.

9. WHO. Program on mental health;WHOQOL user manual. In: Geneva; 2012

10. Vittinghoff E, Glidden DV, Shiboski SC, McCulloch CE. Regression methods in biostatistics: linear, logistic, survival, and repeated measures models (statistics for biology and health). San Francisco. 2005

11. Ormel JKG, Deeg DJ, Brilman El, VanSonderen E, Relyveld J. Functioning, wellbeing, and health perception in late middle-aged and older people: comparing the effects of depressive symptoms and chronic medical conditions. J Am Geriatr Soc. 1998;46:39-48.

12. Marie LL, Nic JV, Dirk JV. Marital status, quality of life and clinical outcome in patients with heart failure. Heart Lung. 2006;35:3-8.

13. Dominik O, Justine R, Stephen MC, Michel W, Tobias F. Health-related quality of life and risk factor control: the importance of educational level in prevention of cardiovascular diseases. Eur J Pub Health. 2013;24(4):679-84

14. Fenn KM, McCorkle R, DiGiovanna MP. Impact of financial burden of cancer on survivors' quality of life. J Oncol Pract. 2014;10(5):332-8.

15. Kale HP. Self-reported financial burden of cancer care and its effect on physical and mental health-related quality of life among US cancer survivors. Cancer. 2016;122(8):283-9.
16. Lathan CS, Tucker-Seeley R, Zafar SY, Ayanian JZ, Schrag D. Association of Financial Strain with symptom burden and quality of life for patients with lung or colorectal cancer. J Am Soc Clin Oncol. 2016:1732-40.

17. Zhuyan ST, Ping Z, Qiang W, Dan L, Shihua W. Association of financial status and the quality of life in Chinese women with recurrent ovarian cancer. Health Qual Life Outcomes. 2017:15:144.

\section{Ready to submit your research? Choose BMC and benefit from:}

- fast, convenient online submission

- thorough peer review by experienced researchers in your field

- rapid publication on acceptance

- support for research data, including large and complex data types

- gold Open Access which fosters wider collaboration and increased citations

- maximum visibility for your research: over $100 \mathrm{M}$ website views per year

At BMC, research is always in progress.

Learn more biomedcentral.com/submissions 